\title{
Condicionantes e limitantes na aquisição de produtos da agricultura familiar pelo Programa de Alimentação Escolar no estado do Paraná
}

\author{
Rozane Marcia Triches \\ Universidade Federal da Fronteira Sul - Realeza - Paraná - Brasil \\ Mariana Grisa Simonetti \\ Universidade Federal da Fronteira Sul - Realeza - Paraná - Brasil \\ Julian Perez Cassarino \\ Universidade Federal da Fronteira Sul/Campus Laranjeiras do Sul - Laranjeiras \\ do Sul - Paraná - Brasil \\ José Giacomo Baccarin \\ Universidade Estadual Paulista Júlio de Mesquita Filho - Jaboticabal - São Paulo \\ - Brasil \\ Carla Rosane Paz Arruda Teo \\ Universidade Comunitária da Região de Chapecó - Chapecó - Santa Catarina - \\ Brasil
}

\begin{abstract}
Resumo
O objetivo deste trabalho foi analisar as dificuldades e os fatores que condicionam a aquisição de produtos da agricultura familiar para a alimentação escolar pela ótica dos atores sociais em municípios do Paraná. Para tanto, foi utilizada pesquisa qualitativa com entrevistas semiestruturadas com agricultores familiares, gestores, profissionais de extensão rural, membros do Conselho de Alimentação Escolar em oito municípios, com diferentes tamanhos populacionais e de diferentes macrorregiões. Os dados foram avaliados por categorização temática, para posterior análise de conteúdo. Barreiras como planejamento da produção, burocracia, logística, falta de comunicação, entre outras, foram referenciadas diferentemente pelos grupos de municípios e atores como dificuldades no cumprimento da legislação. Nos municípios onde existe maior participação, diálogo e parcerias entre gestores, agricultores, conselheiros e extensão rural há melhor aproveitamento dos recursos do Programa e esse entrosamento é mais evidente em municípios de médio e pequeno porte. Nesse sentido, evidencia-se a importância da existência de políticas públicas para a viabilização de mercados para a agricultura familiar, mas esta só se efetiva com a participação dos atores sociais.
\end{abstract}

Palavras-Chave: Alimentação escolar. Agricultura familiar. Segurança alimentar e nutricional. Desenvolvimento rural. 


\title{
Conditions and constraints in the acquisition of the family farming products to School Feeding Program in Paraná state
}

\begin{abstract}
The objective of this study was to analyze the difficulties and the factors that condition the purchase Family farming's products for school feeding from the perspective of social actors in the Paraná municipalities. Therefore, qualitative research was used with semi-structured interviews with family farmers, managers, rural extension professionals, members of the School Feeding Council in eight municipalities, in different population sizes and different macro-regions regions. The data were evaluated by thematic categorization for further analysis of content. Hurdles such as production planning, bureaucracy, logistic, lack of communication, among others, were referenced differently by groups of municipalities and actors such as difficulties in legislative enforcement. In municipalities where there are more participation, dialogue and partnerships between managers, farmers, advisors and rural extension there is a better utilization of resources that programs offers and this engagement is more evident in small and very small municipalities. In this regard, it highlights the importance of public policy for the viability of markets for family farming, but this is only effective with the participation of social actors.
\end{abstract}

Keywords: School feeding. Family farming. Food and nutrition security. Rural development.

\section{Acondicionantes y limitantes en la adquisición de productos de la agricultura familiar por el Programa de Alimentación Escolar en el estado de Paraná}

\section{Resumen}

El objetivo de este trabajo fue analizar las dificultades y los factores que condicionan la adquisición de productos de la agricultura familiar para la alimentación escolar por la óptica de los actores sociales en municipios de Paraná. Para ello, se utilizó investigación cualitativa con entrevistas semiestructuradas con agricultores familiares, gestores, profesionales de extensión rural, miembros del Consejo de Alimentación Escolar en ocho municipios, con diferentes tamaños poblacionales y de diferentes macrorregiones. Los datos fueron evaluados por categorización temática, para posterior análisis de contenido. Las barreras como planificación de la producción, burocracia, logística, falta de comunicación, entre otras, fueron referenciadas diferentemente por los grupos de municipios y actores como dificultades en el cumplimiento de la legislación. En los municipios donde existe mayor participación, diálogo y alianzas entre gestores, agricultores, consejeros y extensión rural hay mejor aprovechamiento de los recursos del Programa y ese entramado es más evidente en municipios de mediano y pequeño porte. En ese sentido, se evidencia la importancia de la existencia de políticas públicas para la viabilización de mercados para la agricultura familiar, pero ésta sólo se efectúa con la participación de los actores sociales.

Palabras-Clave: Alimentación escolar. Agricultura familiar. Seguridad alimentaria y nutricional. Desarrollo rural.

\section{Introdução}

A comercialização de produtos para a alimentação escolar tem sido um dos espaços privilegiados para possibilitar a construção social de mercados alternativos. Países desenvolvidos e em desenvolvimento têm adotado iniciativas visando aproximar a produção e o consumo de alimentos em âmbito escolar, por meio da compra de agricultores familiares locais. Essas ações são focadas tanto no 
encurtamento da cadeia produtiva de alimentos, na sustentabilidade e no desenvolvimento rural, como também na aproximação com os hábitos alimentares do local e melhoria da qualidade da refeição servida (MORGAN e SONNINO, 2008; IZUMI, ALAIMO E HAMM, 2010; TRICHES e SCHNEIDER, 2010; SOARES, 2013).

O Programa Nacional de Alimentação Escolar (PNAE) é uma das políticas alimentares mais antigas. Sua origem, de caráter predominantemente assistencialista, ocorre por volta de 1930, por influência de um grupo de nutrólogos sociais, entre eles, Josué de Castro. Mais tarde, já com recursos do próprio governo federal, priorizou-se a compra centralizada de alimentos formulados e industrializados, adquiridos de um conjunto selecionado de empresas, por meio de licitação pública e distribuídos para todo o território nacional (TRICHES, 2015).

Na década de 1990 iniciou-se um processo de descentralização da alimentação escolar, passando-se a transferir recursos financeiros federais para estados, municípios e escolas, que ficaram responsáveis pelas compras de alimentos (TRICHES, 2015).

Na Resolução n. 15 de 16 de junho de 2003, o objetivo do PNAE passa a ser o de "suprir parcialmente as necessidades nutricionais dos alunos, com vistas a garantir a implantação da política de Segurança Alimentar e contribuir para a formação de bons hábitos alimentares". Em um primeiro momento, houve o aumento de recursos alocados e do público atendido. Sobretudo, a Resolução n. ${ }^{\circ} 32$ de 2006 promulga entre suas diretrizes, o apoio ao desenvolvimento sustentável, além da promoção de alimentação saudável e adequada e a educação alimentar e nutricional (FNDE, 2016).

Porém, embora as regulamentações do PNAE no Brasil fizessem alusão à segurança alimentar e ao desenvolvimento sustentável, após o processo de descentralização e depois da implantação da política de Segurança Alimentar e Nutricional (SAN), o processo de aquisições públicas para o programa praticamente impedia esta efetivação. A natureza da lei de licitações fazia com que o propósito de adquirir produtos locais de pequenos produtores permanecesse impraticável. Tal obstáculo, em termos formais, pode ser superado a partir da mudança nos princípios e regulamentos das aquisições públicas, que ocorreu em 2009 com a promulgação da Lei n. ${ }^{\circ} 11.947$ e da Resolução n. ${ }^{\circ}$ 38. Essa nova legislação inaugura as tentativas de transformar a retórica em realidade a partir da obrigatoriedade da compra de no mínimo 30\% do recurso de produtos da agricultura familiar com dispensa de processo licitatório (TRICHES, 2015).

Autores (BACCARIN, et al., 2017) ao falarem sobre PNAE no estado do Paraná, indicam que a média do percentual utilizado pelos municípios na compra de produtos da AF em 2014 foi de 26,3\%. No mesmo ano, 60\% dos municípios do Paraná usaram mais de $25 \%$ do recurso enviado pelo FNDE para compra de produtos de AFs. Contudo, esses números ainda não são satisfatórios e em alguns municípios do estado, o artigo 14 da Lei 11.947/09 ainda não é praticado.

Estudos (TURPIN, 2009, TRICHES e SCHNEIDER, 2010) indicam que a compra de produtos da agricultura familiar para o PNAE tem demonstrado potencialidades no que tange aos consumidores, indicando aumento na disponibilidade e na quantidade de alimentos de qualidade nutricional superior, como frutas, verduras e legumes e a valorização de produtos da cultura alimentar regional. Mas, o novo modelo de compras públicas do PNAE ainda está em fase de aprimoramento, e 
dificuldades como, barreiras de entrada e altos custos de transação para o agricultor familiar nos mercados formais ainda persistem (TRICHES e BACCARIN, 2016).

Conforme aponta Soares (2013), a integração de todos os agentes envolvidos na cadeia produtiva de alimentos fornecidos pela agricultura familiar para a alimentação escolar é importante na busca pela garantia da SAN. A implementação do Programa, notadamente no que se refere à aquisição dos produtos da agricultura familiar, demanda essa ligação de ações de atores que exige o redesenho das relações sociais, políticas e econômicas no âmbito local e regional. Compreender estas dinâmicas torna-se um elemento central para a plena execução do PNAE e, nesse sentido, identificar os formatos institucionais construídos nas mais diversas realidades pode possibilitar a sistematização de informações que promovam a implementação do Programa, garantindo que este cumpra seu objetivo de promoção da SAN.

Portanto, este estudo tem por objetivo entender quais os condicionantes na aquisição de produtos da agricultura familiar pelo PNAE no estado do Paraná pela ótica de atores sociais envolvidos em sua execução. Dessa forma, busca verificar quais as dificuldades referidas pelos atores quanto ao processo de aquisição pública da Agricultura Familiar (AF) e identificar quais fatores envolvidos no sucesso dos municípios que conseguiram implementar com mais êxito o artigo 14 da Lei 11.947/2009.

\section{Referencial teórico bibliográfico}

Recentemente, novos regramentos de execução do PNAE foram estabelecidos a partir da Lei Federal $n^{\circ} 11.947$ e da Resolução $n^{\circ} 38^{1 / F u n d o ~ N a c i o n a l ~}$ de Desenvolvimento da Educação (FNDE), promulgadas em julho de 2009 (BRASIL, 2009). Dentre eles, a exigência do uso de no mínimo trinta por cento (30\%) dos recursos do FNDE repassados para estados e municípios para compra de produtos da Agricultura Familiar, local, regional ou nacional para a alimentação escolar.

Conjuntamente, novas diretrizes foram estabelecidas pela Resolução $n^{\circ} 38$ como: a prática da alimentação saudável e adequada; a inclusão da educação alimentar e nutricional no processo de ensino aprendizagem; a descentralização das ações e a articulação, em regime de colaboração, entre as esferas de governo e o apoio ao desenvolvimento sustentável, com incentivos para a aquisição de gêneros alimentícios diversificados, produzidos e comercializados em âmbito local e preferencialmente pela agricultura familiar e por empreendedores familiares, priorizando as comunidades tradicionais indígenas e remanescentes de quilombos (Saraiva et al., 2013). Com isto, o Programa tornou-se importante segmento institucional para aquisição de alimentos da agricultura familiar (BRASIL, 2009).

$\mathrm{Na}$ literatura nacional, pesquisas (TRICHES e SCHNEIDER, 2010; TRICHES e SCHNEIDER, 2012) realizadas antes da Lei 11.947/2009 em municípios gaúchos, que usavam processos licitatórios para as compras de alimentos de AF relatavam obstáculos para participação dos agricultores como a burocracia dos processos de compras, a informalidade dos agricultores e as dificuldades organizacionais. Carvalho (2009), ao analisar experiências exitosas em municípios brasileiros, antes das novas diretrizes de execução do PNAE, ressaltava que o principal entrave para a compra de

${ }^{1}$ A Resolução nº 38/2009 foi revogada posteriormente pelas Resoluções n. ${ }^{\circ}$ 26/2013 e n. ${ }^{\circ} 04 / 2015$. 
produtos da AF era a falta de planejamento, ou planejamento inadequado, do gestor para a execução da compra.

Na literatura internacional, Morgan e Sonnino (2008) referiam como barreiras a falta de políticas alimentares, falha no planejamento e na aplicação dos recursos, déficit de conhecimento e carência de líderes. Estas ajudariam a explicar porque as compras públicas sustentáveis continuariam sendo mais uma inspiração do que a realidade na organização do setor público. Segundo Izumi, Alaimo e Hamm (2010), os procedimentos logísticos para a compra de alimentos diretamente dos agricultores têm sido relatados como uma das principais preocupações e desafios na aquisição de alimentos locais. Estes autores citam o tempo adicional necessário para identificar os agricultores, negociar os termos e coordenar as entregas. Além disso, muitas escolas não teriam condições para armazenar, processar e transformar os alimentos, assim como os agricultores não teriam recursos para se adequar às especificações e exigências das escolas.

Em função do caráter recente da nova legislação, que prevê a dispensa licitatória em prol da Chamada Pública para compras de AF, dentro de um limite anual comercializado por família, são relevantes análises de como aqueles problemas relatados ainda permanecem ou foram/estão sendo ultrapassados nos diversos municípios e estados.

Observa-se na literatura que estudos (TRICHES e SCHNEIDER, 2010; TRICHES et al., 2014; TRICHES e KILIAN, 2016) vêm tentando entender o papel dos atores sociais na implementação das compras públicas de AF para o PNAE. Estes têm evidenciado que, em locais onde as relações sociais são mais próximas e os atores são mais dialógicos e comprometidos, estas aquisições têm mais sucesso, já que os problemas são resolvidos e suplantados mais efetivamente. Portanto, a simples mudança legal não seria suficiente para que as Entidades Executoras (EEx) atuassem em prol disso, mas seria necessário que gestores, agricultores e sociedade civil fossem participativos e desejassem que as mudanças ocorressem.

\section{Metodologia}

A pesquisa desenvolvida teve caráter qualitativo e foi realizada em oito municípios de diferentes estratos populacionais e regiões do estado do Paraná e faz parte de duas pesquisas de caráter misto, realizadas nos estados do Paraná, Santa Catarina, Rio Grande do Sul e São Paulo². Estes oito municípios foram elencados a partir de alguns critérios: $1^{\circ}$ ) foram realizadas buscas em sites dos municípios do estado para reunir todas as chamadas públicas para aquisição de produtos da agricultura familiar nos anos de 2011 a 2015; $2^{\circ}$ ) destes, escolheu-se dois municípios de cada faixa populacional - muito pequenos (abaixo de 20.000 habitantes), pequenos (de 20.000 a 100.000 habitantes), médios (de 100.000 a 500.000 habitantes) e grandes (acima de 500.000 habitantes) de diferentes macrorregiões do estado. Os municípios escolhidos estão relacionados no Quadro 1.

2 Este estudo fez parte de Projeto de Pesquisa Cientifica e Tecnológica desenvolvido a partir das Chamadas MCTI-CNPq/MDS-SAGI No 24/2013 Desenvolvimento Social e Chamada MCTI/Ação Transversal-LEI/CNPq No 82/2013 Segurança Alimentar e Nutricional no Âmbito da UNASUL e ÁFRICA. 
Quadro 1 - Caracterização dos municípios investigados, segundo número de habitantes

\begin{tabular}{|c|c|c|c|}
\hline Município & Habitantes & Faixa Populacional & Identificação \\
\hline Curitiba & 1.746 .896 & Municípios Grandes & $\mathrm{G} 1$ \\
\hline Londrina & 506.645 & Municípios Grandes & $\mathrm{G} 2$ \\
\hline Cascavel & 286.172 & Municípios Médios & $\mathrm{M} 1$ \\
\hline Apucarana & 120.884 & Municípios Médios & $\mathrm{M} 2$ \\
\hline Assis Chateaubriand & 33.028 & Municípios Pequenos & $\mathrm{P} 1$ \\
\hline Laranjeiras do Sul & 30.783 & Municípios Pequenos & $\mathrm{P} 2$ \\
\hline Urai & 11.472 & Mun. Muito Pequenos & MP1 \\
\hline Sulina & 3.397 & Mun. Muito Pequenos & MP2 \\
\hline
\end{tabular}

Fonte: Autores, 2016.

A coleta de dados foi realizada no ano de 2016, onde foram entrevistados agentes sociais envolvidos no PNAE, quais sejam: representantes do setor de compras municipal para alimentação escolar, inclusive nutricionista, denominados de gestores, membro do Conselho de Alimentação Escolar do município, agricultor familiar, funcionário de serviço municipal ou estadual de fomento agrícola e extensão rural (ATER). Para cada grupo de agentes sociais foram aplicados roteiros semiestruturados diferenciados. Os atores entrevistados foram identificados da seguinte forma: gestores (G); Agricultores (AG); conselheiros da alimentação escolar (C) e ATER (A). Esses atores foram selecionados por conveniência, considerando a facilidade de encontra-los e anuência com que poderiam estar respondendo a entrevista. Em cada município foram entrevistadas quatro pessoas, totalizando 32 entrevistas.

Em relação aos municípios, estes foram identificados como: Municípios grandes, Curitiba (G1) e Londrina (G2); Municípios médios, Cascavel (M1) e Apucarana (M2); Municípios pequenos, Assis Chateaubriand (P1) e Laranjeiras do Sul (P2); Municípios muito pequenos, Urai (MP1) e Sulina (MP2) conforme Quadro 1.

Os dados qualitativos foram analisados por categorização temática, utilizando-se a técnica de análise de conteúdo. As categorias utilizadas foram: dificuldades encontradas pelos atores, superação dos obstáculos, órgãos articuladores, interação de atores, influencia do PAA, fornecimento de produtos orgânicos e impactos do PNAE. Para realizar a sistematização e a análise dos dados coletados a partir das respostas das entrevistas, documentos e observações realizadas, foi utilizado o software Nvivo11.

\section{Dificuldades no processo de aquisição pública da Agricultura Familiar para o PNAE}

Ao analisar os oito municípios paranaenses verificaram-se dificuldades referidas pelos atores sociais no cumprimento do artigo 14 da Lei 11.947/09, no que tange às compras de produtos da agricultura familiar para o PNAE. Para tal análise e posterior discussão, a Tabela 1 apresenta o percentual médio de recursos gastos com a aquisição de produtos da AF pelos municípios analisados de 2011 a 2015. 
Tabela 1 - Percentual médio de gastos com a aquisição de produtos da Agricultura Familiar para a Alimentação Escolar, 2011 a 2015, municípios selecionados

\begin{tabular}{ccccccc}
\hline Município & $\mathbf{2 0 1 1}(\%)$ & $\mathbf{2 0 1 2}(\%)$ & $\mathbf{2 0 1 3}(\%)$ & $\mathbf{2 0 1 4}(\%)$ & $\mathbf{2 0 1 5}(\%)$ & Média (\%) \\
\hline Curitiba & 0,00 & 0,03 & 1,0 & 0,00 & 4,0 & 1,01 \\
\hline Londrina & 0,00 & 7,34 & 9,0 & 12,0 & 33,0 & 12,27 \\
\hline Cascavel & 38,13 & 21,88 & 41,5 & 27,5 & 16,0 & 29,00 \\
\hline Apucarana & 28,62 & 26,10 & 29,0 & 10,0 & 85,0 & 35,74 \\
\hline $\begin{array}{c}\text { Assis } \\
\text { Chateaubriand }\end{array}$ & 42,49 & 47,65 & 66,0 & 32,0 & 46,0 & 46,83 \\
\hline $\begin{array}{c}\text { Laranjeiras do } \\
\text { Sul }\end{array}$ & 30,20 & 24,74 & 36,0 & 28,0 & 35,0 & 30,78 \\
\hline Uraí & 30,20 & 8,30 & 41,0 & 34,0 & 8,0 & 24,3 \\
\hline Sulina & 0,00 & 38,03 & 42,0 & 41,0 & 35,0 & 31,21 \\
\hline
\end{tabular}

Fonte: Autores a partir de dados do FNDE, 2017.

É notável a diferença no atendimento do artigo 14 ao analisar os locais sob o critério de estratificação populacional. Municípios de grande porte, na média dos cinco anos analisados, obtiveram resultados abaixo dos $30 \%$, enquanto que os locais de porte médio, pequeno e muito pequeno, apresentaram maiores percentuais de compra, alguns ultrapassando o mínimo exigido. Verificou-se que quatro municípios apresentaram percentual médio que atendia à legislação e um deles encontrava-se muito próximo. Considerando apenas o ano de 2015, observa-se que cinco municípios atenderam a legislação, inclusive um de grande porte. Estes números indicam, nesta amostra, a necessidade de maior tempo para adaptação à Lei dos municípios maiores, se comparado aos demais.

Considerando o tamanho dos municípios, verifica-se na Tabela 2, que o número de problemas levantados em cada estrato populacional não diferiu muito entre eles. Os municípios muito pequenos foram os que mais relataram problemas (7), se comparado aos demais. Por outro lado, observaram-se diferenças entre eles no que diz respeito ao tipo de dificuldades relatadas.

As duas problemáticas mais citadas foram referentes ao planejamento da produção e suas questões inerentes (a influência do clima, a quantidade insuficiente produzida, a variedade de produtos ofertados, a organização conforme a necessidade do cardápio e as solicitações de compras conforme a sazonalidade) e a burocracia do processo (dificuldades com as chamadas públicas ou outros processos de compras e com a necessidade documental). 


\section{Tabela 2 - Número de municípios que relataram dificuldades no abastecimento de alimentos provenientes da agricultura familiar para o PNAE e número de dificuldades relatadas em cada grupo de acordo com o tamanho dos municípios, 2015}

\begin{tabular}{|c|c|c|c|c|c|}
\hline \multirow[b]{2}{*}{ Dificuldades } & \multicolumn{4}{|c|}{ Municípios } & \multirow[b]{2}{*}{$\begin{array}{l}\text { Total de locais que } \\
\text { relataram a } \\
\text { dificuldade }\end{array}$} \\
\hline & $\begin{array}{l}\text { Mt. } \\
\text { Pequeno }\end{array}$ & Pequeno & Médio & Grande & \\
\hline $\begin{array}{l}\text { Planejamento da produção - } \\
\text { clima, quantidade, variedade, } \\
\text { organização, sazonalidade. }\end{array}$ & 1 & 2 & 2 & 2 & 7 \\
\hline Burocracia & 2 & 1 & 1 & 2 & 6 \\
\hline Logística & 1 & - & 2 & 2 & 5 \\
\hline $\begin{array}{c}\text { Falta de comunicação - diálogo } \\
\text { - divulgação }\end{array}$ & 1 & 1 & - & 1 & 3 \\
\hline Exigência sanitária & - & 1 & 1 & 1 & 3 \\
\hline Assistência técnica & 1 & - & - & 1 & 2 \\
\hline $\begin{array}{c}\text { Resistencia das } \\
\text { cozinheiras/alunos }\end{array}$ & 1 & - & 1 & - & 2 \\
\hline $\begin{array}{c}\text { Atraso pagamento aos } \\
\text { agricultores }\end{array}$ & 1 & 1 & - & - & 2 \\
\hline Qualidade de produtos & - & - & 1 & - & 1 \\
\hline Total de dificuldades relatadas & 7 & 5 & 6 & 6 & \\
\hline
\end{tabular}

Fonte: Autores, 2017.

Em relação ao planejamento da produção, verifica-se nos depoimento abaixo, a dependência que os agricultores têm da natureza, e, nesse sentido, a dificuldade no abastecimento de mercados como o PNAE.

[...] ah, sempre tem é... às veis o tempo não colabora, às veis tu tem um produto sobrando, o outro tá faltando. Sempre tem dificuldade. Isso tem... a época. As veis o produto é daquela época e você não consegue (AG/ $\mathrm{MP} 2$ ).

[...] sempre são alimentos frescos né. Porém, às vezes não chega no dia adequado né. Por exemplo, hoje serviria... teria que ser alface... eles não conseguem trazer alface, trazem outros produtos né em pouca quantidade só pra atender a demanda né ( $\mathrm{C} / \mathrm{P} 2)$.

Neste sentido, as condições climáticas, interferem na quantidade e na variedade dos produtos fornecidos e, por consequência, na monotonia do cardápio como cita um gestor: "só banana. Se dependesse, seria só banana!" (G/P1).

[...] a quantidade de alunos é muito grande e aquilo que eu falei antes... a maioria é grãos... então... talvez né, a gente tenha falta de algum produto. De variedade né. Então é folhosa: em época da folhosa, tem época que aqui não produz fruta nenhuma $(\mathrm{A} / \mathrm{P} 1)$.

A parte de plantio ainda deixa a desejar. Por que eles não têm variedade. $E$ às vezes nem tem quantidade pra suprir a demanda $(\mathrm{C} / \mathrm{M} 1)$.

A maior mudança foi o pessoal se adequar a forma de trabalhar, de projetar o que ele vai plantar, para estar colhendo na época certa, esse daí foi o maior desafio $(\mathrm{C} / \mathrm{M} 2)$. 
No estudo de Barone et al. (2016) sobre oferta de frutas e hortaliças da AF na alimentação escolar em municípios da região administrativa de São Paulo, foi observado o mesmo entrave sobre a variedade de produtos e qualidade dos mesmos. Os gestores relatavam que a variedade era pequena muitas vezes por conta da chuva, ou porque entregavam no final da safra, resultando em perda da qualidade dos alimentos.

Em entrevista com atores dos municípios de São Miguel de Boa Vista (SC) e Maravilha (SC) sobre os desafios e dificuldades da AF para o PNAE, Motter e Arruda (2012) também verificam dificuldade no planejamento de entrega de alimentos, conforme os gestores dos municípios colocam, o planejamento, na grande maioria das vezes é seguido, porém problemas como o excesso de chuva ou a ocorrência de geada são os fatores que mais comumente comprometem a entrega planejada, segundo os entrevistados.

Em um estudo de Machado et al. (2010) sobre as compras de produtos da agricultura familiar pelo PNAE em alguns municípios brasileiros, dentre as dificuldades, a mais citada foi a quantidade insuficiente de alimentos para atender todas as refeições escolares, além da falta de variedade de alimentos diante das necessidades do cardápio. Neste contexto, nota-se a importância de um potencial para a promoção de estratégias de melhoria da compra de alimentos da agricultura familiar pelo PNAE, e ainda o incentivo à agricultura familiar no Brasil.

[...] dificuldade dos agricultores né, aumentar a produção né [...] também os que não entregavam ainda pro PAA tiveram mais dificuldades em aumentar a produção (A/M1).

E foi aí que o cardápio só deu furo. Porque eles acabavam pedindo: "ah você qué brócolis", mas eles me entregavam só metade da metade do pedido, sabe. Então eles não me atendiam um item, ou eles me atendiam um item que eu precisava mas não na quantidade que eu precisava $(\mathrm{G} / \mathrm{P} 2)$.

Estas interferências do clima complexificam ainda mais o abastecimento deste mercado, exigindo mais planejamento e organização de ambos os lados, demanda e oferta. Assim, o planejamento de cardápios precisa levar em consideração as características próprias dos alimentos, pois alguns produtos possuem o ciclo produtivo mais longo e outros mais sensíveis às alterações climáticas (sazonalidade), afetando o abastecimento. Concomitantemente, os agricultores familiares necessitam realizar um planejamento da produção, visando auxiliar no controle destas oscilações e garantir uma oferta estável de produtos (SARAIVA et al. 2013).

No que tange à burocracia do processo, em seis municípios houve referência a esta questão que parece ainda ser um problema não totalmente sanado, mesmo com a mudança no processo de compras (dispensa licitatória por Chamada Pública) a partir da Lei 11.957/2009. Atores destes municípios referem isto quando falam da administração e organização do programa. "Seria a parte da documentação, por que precisa ser tudo certinho, e a gente como não lida muito com isso com papelada sabe, se perde mais fácil" (AG/M2).

Esta questão foi citada principalmente por municípios de grande porte e muito pequenos.

[...] a própria questão da burocracia, por que hoje infelizmente é o ditado "é mais fácil complicar do que facilitar" né. Então a gente tem muitos 
lugares, apesar que tem uma resolução muito clara, a resolução 26 do FNDE que rege toda questão de como deve ser montado uma chamada e todo processo, ainda há por parte do gestor público a dificuldade em montar chamadas né, e as vezes em vês de fazerem chamadas fazem pregão né, esta é uma questão (AG/G1).

Olha é mais a parte burocrática né mais do projeto, por que é muito documento. É difícil eu né todos os documentos dos agricultores. $\mathrm{E}$ a prestação de contas também não é fácil ne (A/MP2).

A questão burocrática envolve documentação, tornando difícil o arranjo das tarefas públicas por somente alguns membros. Contudo, o grande desafio não depende só do envolvimento de membros realizando suas tarefas, mas também do bom senso dos mesmos no que se refere a preparo das tarefas, encaminhamento de papéis e prazo de entrega.

Em um estudo realizado por Marques et al. (2014) sobre dinâmica de fornecimento de produtos da agricultura familiar em Araripe-Ceará, as reflexões de agricultores familiares apontam grande dificuldade em se manter no processo. Por maior que sejam suas capacidades produtivas para escoar sua produção para as escolas municipais, AFs preferem permanecer fora desse mercado, devido às burocracias do programa.

O terceiro item mais citado foi referente à logística, que só não foi considerada pelos municípios pequenos." [...] as dificuldades as vezes né na logística, por que os valores que eles colocam não está somado a logística e o valor que agente tem pra entregar, certo" (AG/G1).

Esse ano que a gente viu os editais percebeu que o que dificulta bastante é a questão da logística, por que a gente não tem uma central de abastecimento. As cooperativas muitas vezes elas não tem perna para entregar para todas as escolas, e principalmente as menores elas sentem bastante essa dificuldade $(\mathrm{G} / \mathrm{G} 2)$.

A chamada pública sai atrasada [...] não sei se já começaram a entregar produtos, já começaram as aulas, não sei se cada cooperativa sabe quanto vai entregar para as escolas, outra dificuldade é poder entrar com essa central de recebimento, se fosse fazer um espaço físico, um barracão para essa questão de recebimento, distribuição, o grande dificultador é isso $\left(A / G_{2}\right)$.

No estudo de análise da inclusão da agricultura familiar na alimentação escolar no Estado de São Paulo, Belik e Corá (2012) apontam que apesar do objetivo da nova lei de injetar mais recursos na região por intermédio dos produtores rurais (promovendo um círculo virtuoso de aquecimento da economia local, gerando mais ocupações e oportunidades, apoiando os agricultores a ingressarem em outros mercados além do institucional), os bons propósitos na pratica são de difícil realização quando se trata de grandes municípios, com dificuldades logísticas importantes para abastecer as escolas, dado ao grande número de pontos de entrega, as dificuldades de armazenamento dos produtos, condições de manipulação, transporte e outros.

Uma dificuldade semelhante é encontrada em um estudo feito por Ciro e Freitas (2014) no município de Viçosa (MG). Segundo relatos de agricultores, as estradas que dão acesso às comunidades rurais encontram-se em más condições o 
que prejudica o escoamento da produção. Além de que, a gestão dos custos dos empregados na produção, incluindo transporte, não é realizada pelos produtores, o que implica em não saber o ganho real com a produção, fazendo com que os agricultores tenham dificuldades e insegurança no processo de vendas para o PNAE.

A falta de comunicação entre os setores e atores, além da divulgação dos processos de compras junto aos agricultores, também foi referenciado por três municípios, um grande, um pequeno e um muito pequeno.

\footnotetext{
O que aconteceu esse ano aqui foi que às vezes a gente já tinha, já estava tudo certo o que ia pegar... já tinha tido reunião com os agricultores, mas acabou vindo agricultores procurar a gente depois, ai não tinha mais como entrar. Falta de comunicação [...] na verdade sempre ficou tudo pra educação né... pra nós. Então a gente sempre tá em contato com a EMATER, a secretaria da agricultura... só que acaba sempre os $\operatorname{mesmos}(\mathrm{G} / \mathrm{P} 1)$.
}

A questão da falta de comunicação é um problema relatado por vários estudos (BACCARIN et. al., 2017; MOSSMANN et. al., 2017; TRICHES e BACCARIN, 2016), que evidenciam a necessidade dos atores estarem afinados e em perene interação para que possam suplantar os desafios do processo e que quando isso não ocorre, a política tem menos chance de ser exitosa.

Outro item bastante explorado na literatura e frisado aqui em três municípios é o desafio dos agricultores que produzem em baixa escala e que querem processar produtos principalmente de origem animal, em conseguirem se adequar à legislação sanitária. Um dos gestores de um município de grande porte considerou que:

O que a gente também teve dificuldade no último chamamento foi com a carne de peixe em relação a exigências de rotulagem, vigilância sanitária, que tem aquela fiscalização. E assim a vigilância sanitária ela tem uma exigência não só em relação a esses produtos, em relação a qualquer item que seja ofertado. Eles fazem as visitas nas unidades e se tiver alguma coisa que não está correto eles vão impedir o fornecimento (G/G2).

Triches e Schneider (2010) relatam que a mesma problemática foi encontrada no município de Dois Irmãos/RS, pois os agricultores familiares daquele município enfrentaram dificuldade em atender os padrões de qualidade normativos dos produtos agro industrializados, mais especificamente os relacionados às questões sanitárias e às formalidades exigidas para sua comprovação.

Em dois municípios foram colocadas as questões relativas à falta de assistência técnica. Esta é uma questão já evidenciada em alguns estudos (MOSSMANN et. al., 2017 e BALEM et. al., 2016), nos estados do Rio Grande do Sul e Santa Catarina. Os mesmos estudos indicam que os agricultores necessitam de apoio e assessoria técnica para relocalizar e reordenar a lógica da produção, mas a extensão rural pública não tem sido hábil para fazer isso.

Dois municípios frisaram a questão da resistência das merendeiras. Belik e Corá (2012) após avaliação da inclusão de alimentos da agricultura familiar nas escolas do estado de São Paulo constataram dificuldade na aprovação das merendeiras aos produtos da agricultura familiar por não possuírem um padrão uniforme no produto entregue, o que pode gerar insatisfação dos alunos e rejeito da comida. 
[...] foi o local mais difícil que eu tive de enfrentar. Tive problemas sérios, das crianças não comer. Então eu tive pessoas que trabalhavam lá que iam fazer batata com mandioca. Eu tive uma funcionária que falava lá "aí eca", sabe fazia aquela cara de refugo de nojo. A criança é lógico, você é o espelho dela, a criança te copia (G/MP1).

Elas falam, ah a criança não gosta, não precisa mandar. Não, não tem não precisa mandar. Vocês tem que incentivar. [...] a gente sempre procura orientar as merendeiras pra mudar a forma de preparo... mas a gente incentiva (G/P1).

As queixas relacionadas aos produtos da agricultura familiar podem ser resultado da falta de capacitação das merendeiras, visto que antes desta política, o lanche escolar era predominantemente produzido sem muita preparação e variação de cardápio. Com os produtos in natura e diversificados é necessário incentivo para que cursos de capacitação de merendeiras sejam realizados periodicamente, a fim de solucionar dificuldades relativas ao assunto. Dalrot (2002) recomenda que a capacitação técnica das pessoas envolvidas no processo de preparo da alimentação escolar é uma questão importante para a operacionalização de um programa de alimentação escolar. Ainda, Carvalho et al. (2008) consideram que, quanto à promoção de hábitos alimentares saudáveis, destaca-se o trabalho das cozinheiras, profissionais envolvidas diretamente no preparo e distribuição da alimentação escolar. As merendeiras desenvolvem uma forte relação de afeto com as crianças, desempenhando o papel de cuidadoras, o que extrapola uma função específica de preparo e distribuição de alimentos.

De outra parte, também houve em dois municípios o relato de que as prefeituras tiveram problemas com o pagamento dos agricultores, o que leva à desconfiança dos mesmos no processo. Desconfiança esta que já é um sentimento existente nos agricultores, mesmo antes de acessarem as políticas do estado.

Por fim, outro entrave que foi citado, mas apenas por um município de médio porte, foi a questão da qualidade dos produtos que vinham da agricultura familiar.

Existem algumas frutas que são meio complicadas, tipo a banana, tem a cenoura também que as vezes já vem assim bem estragada, a banana muito madura, a gente espera um dia depois a banana já ta com a casca já preta as crianças não comem, por que são muito enjoados (C/M1).

Conforme o que apontam Silva e Silva (2011), o problema de padronização dos produtos se dá devido à produção concentrada (safra e entressafra) e à natureza biológica (perecibilidade) da produção agrícola, a variabilidade qualitativa da matériaprima é inevitável. Portanto, a falta de padronização tem afetado diretamente a comercialização de produtos agrícolas no mercado. Há que se frisar, porém, que os outros sete municípios, falaram muito bem da qualidade do produto destes fornecedores, elogiando-os, sobremaneira, indicando a boa vontade dos mesmos quando havia necessidade de trocas, por exemplo. Isso vem ao encontro de outros estudos onde a melhor qualidade destes produtos foi um dos motivos pelos quais começaram a comprar de agricultores (TRICHES et al, 2014).

Se comparada a realidade dos municípios grandes, médios, pequenos e muito pequenos, verifica-se que nos grandes são mais frequentes as queixas com a logística, burocracia e capacidade de abastecimento dos agricultores; em municípios médios, somam-se a estes problemas, outros, como resistência de merendeiras e 
qualidade dos produtos. Já em municípios pequenos e muito pequenos, atrasos no pagamento dos agricultores e falta de comunicação são questões comuns.

Além de tentar entender como as dificuldades se distribuíam de acordo com o tamanho dos municípios, também se buscou diagnosticar como elas aparecem segundo o grupo de atores entrevistados. Na Tabela 3, observam-se diferentes dificuldades apontadas na visão dos quatro grupos de atores sociais. Para o conjunto dos municípios, verifica-se que, gestores são os que mais referem dificuldades (15 referências), seguidos de perto pelos agricultores (14 referências).

Tabela 3 - Número de relatos sobre dificuldades no abastecimento de alimentos provenientes da agricultura familiar para o PNAE sob o ponto de vista dos atores sociais dos municípios pesquisados, 2015.

\begin{tabular}{|c|c|c|c|c|c|}
\hline \multirow{2}{*}{ Dificuldades } & \multicolumn{4}{|c|}{ Atores Sociais } & \multirow[b]{2}{*}{ Total } \\
\hline & Agricultores & ATER & CAE & Gestão & \\
\hline $\begin{array}{l}\text { Planejamento da produção - } \\
\text { clima, quantidade, variedade, } \\
\text { organização, sazonalidade. }\end{array}$ & 5 & 3 & - & 6 & 14 \\
\hline Logística & 4 & 3 & - & 1 & 8 \\
\hline Burocracia & 3 & 1 & - & 2 & 6 \\
\hline $\begin{array}{c}\text { Falta de comunicação - } \\
\text { diálogo - divulgação }\end{array}$ & 1 & - & - & 2 & 3 \\
\hline Exigência sanitária & - & 1 & - & 1 & 2 \\
\hline Assistência técnica & 1 & - & - & 1 & 2 \\
\hline $\begin{array}{c}\text { Resistencia das } \\
\text { cozinheiras/alunos }\end{array}$ & - & - & 1 & 1 & 2 \\
\hline $\begin{array}{c}\text { Atraso pagamento aos } \\
\text { agricultores }\end{array}$ & - & 1 & - & 1 & 2 \\
\hline Qualidade de produtos & - & 1 & - & - & 1 \\
\hline Total de dificuldades relatadas & 14 & 10 & 1 & 15 & \\
\hline
\end{tabular}

Fonte: Autores, 2017.

A dificuldade de planejamento da produção é a mais citada por gestores, agricultores e extensionistas rurais. Cinco agricultores relatam que as questões de clima, quantidade, variedade para abastecer o PNAE são desafiadoras. Os gestores concordam com as dificuldades relativas à produção dos produtos pelos AFs e citam as dificuldades que os mesmos têm em se organizarem para atender a demanda. Consideram que a produção é pequena e pouco variada.

Outras questões relevantes para os agricultores são à logística e a burocracia. Já para os gestores, as questões são de cunho mais diverso, indo além destes pontos, como a falta de comunicação, exigências sanitárias e resistência das cozinheiras. A extensão rural concorda com os gestores no que se refere ao atraso de pagamentos e no problema da formalização sanitária. Finalmente, os conselheiros do CAE apontam para a resistência dos profissionais que atuam nas cozinhas.

\section{Como superar as dificuldades?}

Em municípios com população muito pequena, como Sulina, percebe-se que as mudanças adotadas se direcionam para a criação de associações entre agricultores do município. "No inicio foi criada uma associação dos Agricultores para dar apoio pra eles, eu acho que foi a maior ação que já foi feita, orientar, na parte da higiene e 
qualidade" (G/MP2). Esta ação pôde servir como forma de melhorar as questões de regularidade e produção, problema que mais os afetava.

Esta solução também foi uma ação do município de grande estratificação populacional, onde o agricultor relata a criação de associações para agricultores como forma de superação das dificuldades.

Olha nós da AOPA-Associação de Agricultura Orgânica do Paraná, estamos conseguindo superar isso com a organização de grupo né. Porque a gente trabalha em rede, a gente se organiza em grupo. [...] Questão do planejamento da produção para melhor organização também (AG/G1).

Neste sentido, a organização por meio de associações e cooperativas colabora para que problemas burocráticos e logísticos sejam suplantados.

Percebe-se que cada local conta com um entrelaçado de aspectos que precisam ser levados em conta quando abordados mecanismos que os municípios usam para suprir a obrigatoriedade do Artigo 14. Como Londrina, por exemplo, que optou por trabalhar com a descentralização da alimentação, considerando ser mais adequado à sua realidade, apesar de onerar o preço do produto final. Essa opção segue na contramão do que outros estudos apontam, alegando que a centralização facilitaria aos agricultores, já que entregariam em apenas um ponto (SILIPRANDI e BELIK, 2012).

Já o município de Assis Chateaubriand, que tem se destacado no alcance dos $30 \%$ oriundos da agricultura familiar, realizou movimento contrário, centralizando a entrega da alimentação escolar. O município conta com uma central de recebimento e depósito dos produtos destinados para a alimentação escolar. As entregas passaram a ser feitas semanalmente em quantidades previamente estipuladas. Assim, ao mesmo tempo em que foi estabelecido o monitoramento de se respeitar o cardápio, a gestão facilitou a logística para os agricultores.

Um discurso semelhante em todos os municípios pesquisados é a necessidade de manter o diálogo entre os envolvidos no programa. O firmamento de parcerias é uma realidade pertinente a todos os locais analisados, embora exista uma distinção entre o nível de intensidade dos vínculos que são estabelecidos pelas partes envolvidas em cada um dos municípios. De acordo com Spink e Silva (2010), a participação de variados setores implica reconhecer que os atores sociais não são os únicos a agir publicamente. Pressupõe-se que quanto mais interfaces forem estabelecidas, maiores são as possibilidades das mudanças serem implementadas.

É através do tempo mesmo, com várias tentativas que a gente vem fazendo. E como falei, fazendo audiência, correndo atrás né, a divulgação foi bem ampla mesmo, com os órgãos envolvidos: MDA, EMATER, Conab. Mas a gente conversando com os agricultores, internamente na prefeitura e os chamamentos de 2014, tivemos um bom resultado $(G / G 1)$.

[...] muita conversa, muito jogo de cintura. Nós temos funções diferentes, eu sou nutricionista, você é cozinheira, você é diretora, você é professora e você é zeladora, mas estamos em um mesmo patamar e pelo mesmo objetivo. Então eu não sou mais que você e você não é mais do que eu, então vamos fazer a mesma lida para atingir nossos objetivos (G/MP1).

Nos municípios de Grande Porte, existe a parceria entre agricultores e a gestão, no entanto, identificou-se pouca participação do Conselho de Alimentação 
Escolar (CAE). Nestes locais constata-se que os representantes do órgão têm um discurso que se limita ao conhecimento da existência da obrigatoriedade do Artigo 14 do PNAE e que a individualidade dos atores, devido ao tamanho das cidades, é um fator que prejudica o diálogo e a execução do Programa.

Em contrapartida, nos municípios pequenos e muito pequenos é possível visualizar que os atores mostram-se envolvidos com a temática de planejar, acompanhar, fiscalizar e prestar contas no que diz respeito à alimentação escolar. Presume-se que nestes municípios, em que a compra de gêneros alimentícios provenientes da agricultura familiar oscila em torno de 30\%, há de fato maior aproximação entre os atores locais. Isso é possível graças ao diálogo e cobrança por parte dos envolvidos, bem como a criação de associações entre agricultores para potencialização das políticas e programas implementados.

Para os AFs entrevistados foram importantes, além da maior organização por meio de associações e cooperativas, o auxílio da Extensão Rural, o diálogo com o nutricionista, com os técnicos da Secretaria da Agricultura, da AGRIVEL, da EMBRAPA e também de instituições de Ensino superior (como os Centros Colaboradores em Alimentação e Nutrição do Escolar - CECANEs) e instituições Beneficentes (Associação de Agricultura Orgânica do Paraná- AOPA). Os gestores identificaram como formas de superação, a aproximação com os AFs, reuniões conjuntas com a Emater e outros setores e as capacitações oferecidas principalmente pelas Instituições de Ensino Superior para os diversos atores envolvidos com o programa (AFs, Conselheiros, Nutricionistas, etc.).

Assim, nos discursos observaram-se envolvimentos diferenciados da Emater e dos Conselhos de Alimentação Escolar com o Programa nos diversos municípios. Em alguns, foram identificadas participações substanciais destes atores, em outros municípios, elas pareceram incipientes. No entanto, percebe-se que a intersetorialidade e a participação social no processo é uma ação necessária, mesmo para os que ainda estão se organizando para atender o Artigo 14 da Lei 11.947/2009, como os municípios de grade porte.

Nós estamos fazendo reuniões com eles, com a EMATER, com a agricultura... secretaria de agricultura pra tá passando para os agricultores, por que isso é uma coisa que ainda tá difícil [...] tamo tentando, para que eles plantem outros produtos né (G/M1).

Contrastando as diferentes realidades, este estudo traz elementos que indicam que interfaces e estratégias fazem diferença nos processos de mudança. Verifica-se que nos municípios maiores há maior dificuldade de integração entre os atores, diferentemente de municípios pequenos, os quais conseguem realizar maior numero de interfaces, facilitando as interações e estratégias de superação dos problemas existentes.

No que se refere à maior aceitação destes produtos por merendeiras e alunos, registra-se que em alguns municípios foram realizadas capacitações com este público. Além disso, foram feitas mudanças na forma de planejar o cardápio, de preparar os alimentos e na entrega dos gêneros.

Os distritos é entregue os alimentos pelo depósito aqui, eles trás no depósito e eles entregam, as escolas da cidade nós entregamos. [...] Eu 
acho que o depósito tinha que entrega é tudo [...] acontece muito de você entrega um produto, quando chega em casa, a reclamação no outro dia do produto tava estragado, ou deteriorado, mas por que a pessoa não coloco ele em local adequado (AG/P1).

Por fim, foram citados os auxílios de outras políticas, como o PAA, programas de crédito e financiamento e o custeio por meio do SEBRAE para certificação de alimentos orgânicos, por exemplo, indicando uma preocupação constante com a qualidade dos produtos e com a visibilidade e importância deste Programa para os agricultores familiares e para a nutrição dos escolares.

\section{Considerações finais}

Quanto ao cumprimento do Artigo 14 da Lei do PNAE, o presente trabalho demonstra diferenças entre os municípios pesquisados quanto às dificuldades e formas de superá-las. Pode-se constatar que os municípios de grande porte são os que enfrentam com mais dificuldade os problemas e que estes não têm sido suplantados, dentre outras questões, pelo maior distanciamento entre os atores envolvidos. Já municípios de médio porte, ou os pequenos e muito pequenos demonstram mais facilidade de cumprir o Artigo 14 decorrente da maior aproximação entre os atores locais, notadamente entre agricultores rurais e gestores.

Este estudo corrobora com outros já realizados, no sentido de destacar o quão importante é o papel dos atores sociais e suas interfaces para que os programas e políticas tenham êxito. Estudos identificando estas questões são importantes para evidenciar onde estão os pontos fulcrais que distinguem as EEx que conseguem adquirir produtos da AF e as que não conseguem.

As aquisições da agricultura familiar para a alimentação escolar configuram-se como exemplo concreto da importância da intersetorialidade na formulação e implementação de políticas de SAN. Para tanto, ao pensar a execução deste tipo de política, estudos como este revelam grande representatividade e levantam questões que devem ser tomadas como elemento fundante do cumprimento dessas políticas. Torna-se fundamental que novos estudos sejam feitos para esclarecer melhor os pontos, fornecendo os instrumentos e condições para que a intersetorialidade do programa se efetive.

A partir das evidências constatadas, este estudo serve como subsídio para melhorar a execução do Programa e para novas janelas para estudos futuros, visto que a análise aprofundada de qualquer uma das frações e, em diferentes locais e realidades, podem gerar novas linhas de discussão. 


\section{REFERÊNCIAS}

BACCARIN, J.G. et al. Indicadores de Avaliação das Compras da Agricultura Familiar para Alimentação Escolar no Paraná, Santa Catarina e São Paulo. Rev. Econ. Sociol. Rural vol. $55 \mathrm{n}^{\circ} .1$ Brasília Jan./Mar. 2017.

BALEM, et al. O papel da extensão rural na construção do mercado institucional da alimentação escolar no Brasil. Rev. Raízes, v.36, n. 2, jul-dez, Campina Grande- PB, 2016.

BARONE, B. et. al. Frutas e hortaliças da agricultura na alimentação escolar. Vigil. sanit. Debate, v.4, n.3, p.86-95, 2016.

BELIK, W.; CORÁ, M.A. Chamada Pública: instrumento legal de compras da agricultura familiar para a alimentação escolar. In: Projeto Nutre SP: análise da inclusão da agricultura familiar na alimentação escolar no estado de São Paulo, Instituto Via Pública, 2012.

BRASIL. Poder Legislativo. Lei ${ }^{\circ} 11.947$, de 16 de junho de 2009. Dispõem sobre o atendimento da alimentação escolar e do Programa dinheiro direto na escola aos alunos da educação básica. Diário Oficial da União 2009; 16 jun. Disponível em: https://www.fnde.gov.br/fndelegis/action/UrlPublicasAction. php?acao=getAtoPublico\&sgl_tipo $=$ LEI\&num_ato $=00011947 \&$ seq_ato $=000 \& v \mid r$ ano $=2009 \&$ sgl_orgao=NI. Acesso em: 07 de out 2016 .

BRASIL. Resolução/CD/FNDE nº 38 de 16 de julho de 2009. Dispõe sobre o atendimento da alimentação escolar aos alunos da educação básica no Programa Nacional de Alimentação Escolar (PNAE). Diário Oficial da União 2009; 17 jun. Disponível em:

https://www.fnde.gov.br/fndelegis/action/UrIPublicasAction.php?acao=getAtoPubli co\&sgl_tipo $=$ RES\&num_ato $=00000038 \& \mathrm{seq}$ ato $=000 \& v \mid r$ ano $=2009 \& s g \mid$ orgao $=C$ D/FNDE/MEC. Acesso em: 07 de out. 2016.

CARVALHO, A.T. et al. Programa de Alimentação Escolar no município de João Pessoa - PB, Brasil: as merendeiras em foco. Interface - Comunicação, Saúde, Educação, v.12, n.27, p.823-834, out./dez. 2008.

CARVALHO, D. G. Licitações sustentáveis, alimentação escolar e desenvolvimento Regional: uma discussão sobre o poder de compra governamental a favor da sustentabilidade. Planej Pol Públicas. n.32, p.115-148, 2009.

CIRO, P. M. R. e FREITAS, A. F. de. O Programa Nacional de Alimentação Escolar como indutor de Processos de Desenvolvimento Local em Viçosa. In: VII Encontro Nacional de Pesquisadores em Gestão Social, 2013, Belém-PA. Anais do VII ENAPEGS, 2013. Disponível em: https://conferencias.ufca.edu.br/index.php/enapegs/enapegs2013/ paper/view/1675. Acesso em: 28 set. 2017. 
DAROLT, M.R. Merenda escolar orgânica: Uma mudança de hábito saudável. Rio de Janeiro. Disponível em http://www.planetaorganico.com.br/DaroltMerenda.htm. Acesso em: 28 set. 2017.

IZUMI, B.T.; ALAIMO, K. HAMM, M. W. Farm to School Programs and Their Potential for Meeting School Food Service Goals. Journal of Nutrition Education and Behavior, v.40, n.4, julho/agosto, 2008.

MACHADO, P. M. O. et. al. Características do processo de aquisição de alimentos da agricultura familiar pelo Programa Nacional de Alimentação Escolar: um estudo transversal exploratório do universo de municípios brasileiros. Tese mestrado Universidade Federal de Santa Catarina, Programa de Pós-graduação em Nutrição, Florianópolis, 2013.

MARQUES, A., A. et. al. Reflexões de agricultores familiares sobre a dinâmica de fornecimento de seus produtos para a alimentação escolar: o caso de Araripe, Ceará. Saúde Soc. v.23, n.4. São Paulo. 2014.

MORGAN, K; SONNINO, R. The school food revolution: public food and the challenge of sustainable development. London: Earthscan, 2008.

MOTTER, A. F. ARRUDA, C.R.P. Agricultura Familiar: Desafios e Dificuldades na aproximação com o Programa Nacional de Alimentação Escolar. In: CONVIBRA Saúde - Congresso Virtual Brasileiro de Educação, gestão e promoção da saúde. 2012. Disponível em:

http://www.convibra.com.br/upload/paper/2012/69/2012 69_4079.pdf. Acesso em: 28 set. 2017.

MOSSMANN, M. P. et. al. Interface Between Family Farming and School Feeding: barriers and coping mechanisms from the perspective of different social actors in Southern Brazil. Rev. Econ. Sociol. Rural, vol.55, n.2, p.325-342, 2017.

SARAIVA, E. B.; et. al. Panorama da compra de alimentos da agricultura familiar para o Programa Nacional de Alimentação Escolar. Ciência e Saúde Coletiva, Rio de Janeiro, v. 18, n. 4, abr. 2013.

SILIPRANDI, E.; BELIK, W. A agricultura familiar e o atendimento à demanda institucional das grandes cidades, In: Projeto Nutre SP: análise da inclusão da agricultura familiar na alimentação escolar no estado de São Paulo, São Paulo: Instituto Via Pública. 2012.

SILVA, K. R. D. SILVA, L. A. C. Análise da comercialização e do impacto do PAA e PNAE na condição de vida das famílias agricultoras de Bananeiras, na Paraíba. Tese mestrado. Paraíba: Universidade Federal da Paraíba; 2011. 
SOARES, P. et. al. Fornecimento de alimentos da agricultura familiar para a alimentação escolar: o exemplo do Programa de Aquisição de Alimentos. Segurança Alimentar e Nutricional, Campinas, v.20, n.1, p. 41-51, 2013.

SPINK, P.; SILVA, G.T. A(s) Política(s) Pública(s) e as linguagens da Ação Pública. In: LOUREIRO, M. R. TEIXEIRA. Políticas Públicas e o Desenvolvimento Brasileiro. Editora FGV, 2010.

TRICHES, R.M.; BACCARIN, J.G. Interações entre alimentação escolar e agricultura familiar para o desenvolvimento local. In: TEO, C.R.P.A; TRICHES, R.M. (Org.).

Alimentação Escolar: construindo interfaces entre saúde, educação e desenvolvimento. Chapecó: Argos, v. 1, n.1, p. 89-109, 2016.

TRICHES, R. M.; et al. O Programa de Alimentação Escolar nutrindo o desenvolvimento: ideias e relações inovadoras. In: SCHNEIDER, S; MENEZES, M; SILVA, A.G; BEZERRA, I. (Org.). Sementes e brotos da transição: inovação, poder e desenvolvimento em áreas rurais do Brasil. Porto Alegre: UFRGS, 2014, v. 1, p. 115139 .

TRICHES, R. M. KILIAN, L. Papel dos atores sociais na aquisição de produtos da agricultura familiar para alimentação escolar em municípios paranaenses. Revista do desenvolvimento regional, v.21, n.3, p.159-179, 2016.

TRICHES, R. M. Repensando o mercado da alimentação escolar: novas institucionalidades para o desenvolvimento rural. In: GRISA, C; SCHNEIDER, S. (Org.). Políticas públicas de desenvolvimento rural no Brasil. Porto Alegre: Editora da UFRGS, v. 1, n.1, p. 181, 2015.

TRICHES, R.M. SCHNEIDER, S. Alimentação Escolar e Agricultura Familiar: reconectando o consumo à produção. Saude Soc. São Paulo, v. 19, n. 4, p.933-945, 2010.

TRICHES, R.M.; SCHNEIDER S. Desestruturar para construir: interfaces para a agricultura familiar acessar o programa de alimentação escolar. Estudos Sociedade e Agricultura, v. 20, n.1, p.66-105, 2012.

TURPIN, M., E. A alimentação escolar como fator de desenvolvimento local por meio do apoio aos agricultores familiares. Segurança Alimentar e Nutricional, v.16, n.2, p.20-42, 2009. 
Rozane Marcia Triches, Mariana Grisa Simonetti, Julian Perez Cassarino, José Giacomo Baccarin,

Rozane Marcia Triches. Professora Adjunta do Curso de Graduação em Nutrição e Curso de Pós-Graduação Stricto Sensu em Agroecologia e Desenvolvimento Rural Sustentável Universidade Federal da Fronteira Sul.rozane.triches@gmail.com

Mariana Grisa Simonetti. Graduada em Nutrição pela Universidade Federal da Fronteira Sul.marianagrisa1895@gmail.com

Julian Perez-Cassarino. Professor do Programa de Pós-Graduação em Agroecologia e Desenvolvimento Rural Sustentável da Universidade Federal da Fronteira Sul.julianperez7@gmail.com

José Giacomo Baccarin. Professor da Faculdade de Ciências Agrárias e Veterinárias, campus de Jaboticabal da Universidade Estadual Paulista Júlio de Mesquita Filho.baccarin@fcav.unep.br

Carla Rosane Paz Arruda Teo. Professora do Programa de Pós-Graduação em Ciências da Saúde da Unochapecó. carlateo@unochapeco.edu.br

Como citar: TRICHES, Rozane Marcia et al. Condicionantes e limitantes na aquisição de produtos da agricultura familiar pelo Programa de Alimentação Escolar no estado do Paraná. Redes, Santa Cruz do Sul, v. 24, n. 1, p. 118-137, jan. 2019. ISSN 1982-6745. Disponível em: https://doi.org/10.17058/redes.v24i1.11713. 